\title{
Millet Bahçelerinin Çeşitli Boyutları: Jane Jacobs Bu Projeye Ne Derdi?
}

\author{
Various aspects of public gardens: What would Jane Jacobs \\ say for this project?
}

\section{Meriç Kırmızı}

Ondokuz Mayıs Üniversitesi Fen-Edebiyat Fakültesi, Sosyoloji Bölümü, Samsun, Türkiye; Sosyal Bilimler İleri Araştırmalar Okulu (EHESS), Fransa Japon Vakfı, Paris, Fransa

\section{ÖZ}

Toplum olarak ağaçlara bakış açımızla ilgili ayrışmış durumda olduğumuz ileri sürülebilir. Bir yanda doğal ekosistemlerin savunucuları, öte yanda ağacı değersiz bir engel olarak gören bir bakış açısı var. Bu toplumsal bağlamda, 20।8'den bu yana kentlerimizin gündeminde olan millet bahçeleri projesi özellikle büyük kentlerdeki açı-yeşil alan gereksinimi düşünüldügünde olumlu bir girişim gibi gözükse de, bu projenin tam olarak irdelenmesi gereken birçok boyutu söz konusudur. Bu yazıda millet bahçeleri konusu şimdiye kadar yapılmış araştırmalara dayanarak, ekolojik, ekonomik, siyasal, simgesel-ideolojik ve toplumsal-kültürel boyutlarıyla değerlendirilmektedir. Bu değerlendirmenin ardından, Jane Jacobs'un Büyük Amerikan Kentlerinin Ölümü ve Yaşamı eserindeki özellikle, mahalle parklarına ilişkin çözümlemelerinden yararlanarak, konunun planlama boyutu tartışılmaktadır. Bu çalışmada "Millet bahçelerine Jane Jacobs ne derdi?" sorusuna Jacobs'un adı geçen kitabından esinli yorum ve değerlendirmeler yoluyla bir yanıt aranmaktadır. Böylelikle, Türkiye kentlerinin gündemindeki millet bahçeleri konusu Jacobs'un geleneksel kentsel planlama anlayışı karşısında benimsediği aynı analitik tutumla sorunsallaştırılmaktadır.

Anahtar sözcükler: Analitik planlama; Jane Jacobs; kent parkları; millet bahçesi; yeşil alan.

\begin{abstract}
It can be argued that as a society, we are in a divided situation with respect to our outlook on trees. On the one hand, there are the supporters of natural ecosystem, and on the other, a viewpoint that sees the tree as a worthless obstacle. In this societal context, although the public garden project that has been on the agenda of our cities since 2018 appears to be a positive attempt, considering the open and green space need in particularly large cities, this project has multiple aspects that should be examined thoroughly. In this paper, the topic of public gardens is evaluated based on previous research with its ecological, economic, political, symbolic-ideological, and socio-cultural dimensions. Following this evaluation, the topic's planning dimension is discussed by drawing on Jane Jacobs' analyses, particularly regarding neighbourhood parks in her work, The Death and Life of Great American Cities. In this study, an answer to the question of "What would Jane Jacobs say for the public gardens?" is searched for through interpretations and evaluations, inspired by Jacobs' aforementioned book. In this way, the topic of public gardens on the Turkish cities' agenda is problematized with the same analytical attitude that Jacobs adopted against the traditional urban planning understanding.
\end{abstract}

Keywords: Analytical planning; Jane Jacobs; urban parks; public garden; green space. 


\section{Giriş}

Toplum olarak ağaca bakışımızda birçok konuda olduğu gibi derin ayrılıkların olduğu gözlemlenebilir. Bir yanda, doğanın yağmalanmasına karşı çıkan her kesimden insanın gösterdiği çabalar, buna yönelik toplumsal hareketler ve oluşumlar var. Örneğin, Gezi Parkı direnişi, Validebağ direnişi, Acıbadem Tibaş Parkı Gönüllüleri, Göztepe Özgürlük Parkı'ndan doğan Duyarlı Kentliler Hareketi, Kuzey Ormanları Savunması ve Ya Kanal Ya İstanbul Platformu'nun yanında, siyanürle altın aramaya, mermer ocaklarına, HES’lere, Yeşil Yol'a direnen çeşitli yöre halkları ve Metin Lokumcu, Ali Ulvi ve Aysin Büyüknohutçu gibi yaşamını yitirmiş çevreci insanlar var. Öte yanda, ilk eline testere geçirenin gündelik ağaç kıyımları ve bunu normalleştirip, tersi ağaç-sever yaklaşımları anormalleştiren bir düşünce yapısı da ne yazık ki var.

Çok sayıdaki ikinci gruptakiler için, apartman bahçelerindeki, piknik alanlarındaki ağaçlar ortadan kaldırılması, insanın isteğine göre kolunun kanadının kırılması gereken birer engel gibidir. Kiminin ağaca ölümcül alerjisi vardır. Ötekinin ağaç yüzünden evine böcek girer, anlaşılması güç bir biçimde “ağaç evine zarar verir”. Bir başkası için, ağaç sokak lambasını örter ve karanlık nedeniyle, güvenlik sorunu yaratır. Kiminin yaşadığı alt kat daireye gölge eder. Kiminin de denizi görmesini engeller. Bir diğerinin piknik alanında karavanı$\mathrm{nı}$ istediği yere park etmesini ağacın bir dalı engeller. Yine, sözde eğitimli bir başkası için, yeşil zaten her yerde olan, o nedenle öyle değersiz bir şeydir. Bütün bunlara aynı sırayla şu karşı savlar üretilebilir: Japonya'da polen alerjisi olmayan insan yok gibidir, ama kimsenin aklına bahçedeki ağaçları kesmek gelmez; maske takmak gibi kişisel önlemler almakla yetinirler. Ülkede gün ortasında da güvenlik sorunu var! Ağaç gölgesinden daha istenilesi bir şey olabilir mi? Ağacın denizle buluştuğu bir görünümden daha güzeli var mı? Her yerde yeşil olması bir yana, gerçekte, çoğu zaman çevrede betondan başka bir şey bulunmaz. Bu kişisel gözlemlere dayanarak, toplumun ağaçla ilişkilenme biçiminin birçok konudaki gibi ikircimli olduğu saptaması yapılabilir.

Çevreci bir bakış açısıyla Türkiye'deki kentlerin gündemindeki "millet bahçesi” projesi için, "Ne güzel işte! Betonlaşan kentlerde yeşil alan yapılması,” deyip, geçilebilirdi. Ancak bu kolaycılık olurdu, çünkü konunun ekolojik, politik, simgeselideolojik, ekonomik, toplumsal ve kültürel gibi dikkat edilmesi gereken birçok boyutu var. 20I8'den bu yana ülke gündeminde olan millet bahçeleri üzerine yapılmış akademik çalışma sayısı sınırlı olsa da, bu yazıda öncelikle yapılmış olan çalışmalar ekolojik, politik, simgesel-ideolojik, ekonomik, toplumsal ve kültürel boyutlarıyla derlenmiş, ardından konu Jacobs'un planlama anlayışı çerçevesinde ele alınarak incelenmiştir. Bu inceleme için, Jacobs'un (196I/2017) Büyük Amerikan Kentlerinin Ölümü ve Yaşamı eserinde kent parklarına ve kentin yeşil alanlarına ilişkin ileri sürdüğü düşünceler yol gösterici olmuştur. Böylece, "Jacobs yaşasa ve ülkemiz gündemindeki bu projeyi duysaydı, millet bahçeleri için ne söylerdi?" sorusuna yanıt verilmeye çalışılmıştır.

\section{Yapılan Ulusal Araştırmalar üzerinden Millet Bahçelerinin Çeşitli Boyutları}

Millet bahçesi yapımına ekolojik açıdan yaklaşan çalışmalarda bu projenin korunması gereken Salda Gölü gibi doğal alanlarda insan eliyle yapacağı yıkım değerlendirilmektedir. Buna göre, millet bahçesinin yaratacağı yapılaşma (Çolak, 2020; Ecevit, 2020) söz konusu çevrelerin doğal ekosistemlerine zarar verecektir. Yapılaşmayla birlikte bölgenin gitgide turistikleşip, insan çekmesiyle de bu yerlerin bozulmadan taşıyabileceği insan kapasitesi sınırı zorlanacaktır (Ceylan ve Bulut, 2019).

Diğer bir ekolojik değerlendirme millet bahçelerinin kent merkezlerinde yapıldıkları konum bakımından ortaya çıkabilecek doğal yıkım risklerine ilişkindir. Yıldırım ve Gül (2020) Samsun Millet Bahçesi'ni değerlendirdikleri çalışmada alanın coğrafi konumu bakımından hem sel, şiddetli rüzgâr gibi doğa olaylarına, hem de batısında yer alan sanayi bölgesi nedeniyle sanayi atıklarına açıklığını bir risk olarak göstermişlerdir. Gölönü (2020) İstanbul'daki Atatürk Havalimanı'na yapılacak millet bahçesini yapılan yeni havalimanı nedeniyle kentin kuzey ormanlarına verilen çevre zararının eleştirilerini bastırma girişimi olarak yorumlamaktadır. Pandemi döneminde Atatürk Havalimanı'nın sahra hastanesi yapılacağına ilişkin gazete haberleri de yapılmış, ama bu gerçekleşmemiştir.

İncelenen çalışmalarda millet bahçesi gibi devlet eliyle yürütülen park ve bahçe girişimlerinin yalnızca, kentlerde yeşil alanın artırılmasını amaçlamadı̆̆ı, bunların aynı zamanda, politik anlamda projeleri üstlenici, yıpranmış yönetimler için birer uluslararası saygınlık (prestij) projesi olduğu da dile getirilmektedir. Bir yetkilinin, "Ama Millet Bahçeleri için ortalama 70.000-80.000 m²'lik alanlardan bahsedebiliriz," (Birol ve Aydın, 2019: 494) sözü bu saygınlığın bir ölçüde, mekânsal büyüklüğe odaklı olduğunu ve alanın büyüklüğünün yer seçiminde başlıca ölçüt yapıldığını (Kaştaş Uzun ve Şenol, 2020: 233) düşündürmektedir.

Siyasal boyuta ek olarak, tarih boyunca kentlerin kamusal mekânları kapsamındaki yeşil açık alanların belirli politikaların, belirli yurttaşlık kimliği hedeflerinin izlerini taşıyan, simgesel niteliği bulunan yerler olduğu konuyla ilgili araştırmalarda vurgulanmaktadır. Yani, olay gerçekten de, Gezi Parkı direnişini küçümseyenlerin deyişini tersi amaçla ödünç alarak, yalnızca, “üç beş ağaç meselesi” değildir. Eğer öyle olsaydı, Rize Fındıklı'daki millet bahçesinin ve kıraathanesinin adlarıyla ilgili siyasal tartışma yaşanmazdı (Kepenek, 2020). İçinde mescidi, külliyesi ve kıraathanesiyle 'millet' bahçesi de çok açık ki bir Bomonti 
bira bahçesi değildir; zaten onun da kültürel miras niteliğindeki kimi yapıları yakın geçmişte T.C. Diyanet İşleri Başkanlığı'na devredilmiştir (Gökdemir, 2019).

Kaştaş Uzun ve Şenol (2020) millet bahçelerini Türkiye'nin kamusal yeşil alanlarının tarihsel gelişimi bağlamında inceledikleri çalışmada, geçmiş ve günümüzdeki siyasal projelerin yeşil alanların yaratımında gözettikleri hedefler arasındaki farklılığı modernleşme karşısında gelenekler olarak vurgulamaktadır. Bu yazarların hazırladığı "Gazete başlıklarına göre yapılmış millet bahçelerinin ilk örnekleri ve özellikleri” (Kaştaş Uzun ve Şenol, 2020: 236) tablosunda park olanaklarının niteliklerini özetleyen sütunda belirtilen yapılar ideolojik boyuta ilişkin bir ipucu sağlamaktadır. Aynı biçimde, Ekinci ve Sağlam (2016) genel anlamda kent parklarının zaman içindeki fiziksel değişimlerine karşın, ideolojiyi temsil etme işlevlerinin korunduğu saptamasında bulunmaktadırlar. Öte yandan, aynı yazarlar erken Cumhuriyet döneminde yapılmış kent parklarının günümüz ideolojisinin ürettiği parklardan kentsel dokuya eklemlenme; bütün toplumsal kesimlerin kendileri gibi olmayanlarla karşılaşma olasılıklarını da kapsayan biçimde, özgür kullanımına açıklık ve böylelikle, insanların birbirlerinden bir şeyler öğrenip, gelişmelerine olanak tanınması gibi konulardaki farklılıklarını göstermektedirler. Bu anlamda, Atatürk Orman Çiftliği (AOÇ) gibi erken Cumhuriyet parklarının "sürdürülebilir bir kentsel ve kültürel gelişme"(Ekinci ve Sağlam, 2016: 620) için korunması gerektiğinin önemle altını çizmektedirler.

Millet bahçelerinin yapımının çevresel ve politik etkilerinin yanında, ekonomik etkilerinin de olduğunu aynı çalışmalar saptamaktadır. Bu ekonomik etkiler millet bahçelerinin yer aldıkları kentin ekonomisine yapması beklenen olumlu etkileri, ama aynı zamanda, açık-yeşil alan projeleri üzerinden yaratılan kentsel rantı da kapsamaktadır. Bu ekonomik etkilerden ilki millet bahçelerin bulundukları kentlerde yeni birer kentsel çekim merkezi yaratarak, turistikleşme üzerinden sağlaması beklenen ekonomik gelirle ilgilidir. Ceylan ve Bulut (2019) Salda Gölü örneğinde yaratılacak bu kazançtan kimlerin yararlanacağına şu sözlerle dikkat çekmektedirler: "Millet Bahçesi içerisine kafe, restoran, mescit ve çocuk oyun alanı gibi sosyal donatıların oluşturulacağı ve işletmelerin ihale ile kişilerin işletimine verileceği belirtilmektedir. Millet Bahçesi'ne yapılacak işletmelerin dışardan ihaleye girenlere verileceği ve göl kıyılarının giderek imara ve yapılaşmaya açılacağı yönünde yerel halk üzerinde kaygıların olduğu yapılan görüşmelerde görülmektedir," (Ceylan ve Bulut, 2019: 88). Buna göre, yöre halklarının millet bahçelerinin etkinliklerinden elde edilecek bu kazanca ortak olup, olmayacağı sorusu belirsizliğini korumaktadır.

Diğer çalışmalar "kentin içerisinde, bireylerin farklı rekreatif ihtiyaçlarını karşılayacak bir planlama” (Birol ve Aydın, 2019: 492) öğesi olarak, millet bahçelerinin görünürdeki kentlerin yeşil alanlarını artırıp, kentlileri eşitlikçi bir biçimde yeşil alan- larla buluşturma hedefinin arkasında belirli bir kesime yönelik kâr sağlama hedefinin yatıp yatmadığını sorgulamaktadır. Örneğin, Ekinci ve Sağlam (20I6) bugünkü kent parklarının kamusal alan niteliklerinin yanında, bu mekânlara yüklenen anlam ve onları çevreleyen mahallelere kattıkları ekonomik yarar gerekçesiyle "bir yatırım aracı"na dönüştüklerini Ankara'daki çeşitli "vadi projeleri” üzerinden saptamaktadır (Ekinci ve Sağlam, 2016: 6II). Ekinci ve Sağlam'ın ele aldıkları Ankara örneklerine bakıldığında, çoğunun kentsel dönüşüm alanlarına karşılık geldiği görülmektedir. Bu bakımdan, ilgili yazarların "kamusal alanların kentsel dönüşüm stratejileri için yararlı araçlar”" (Ekinci ve Sağlam, 2016: 620) oldukları saptaması yerindedir.

Aynı biçimde, Gölönü’nün (2020) İstanbul çalışmasında söz konusu millet parklarının şimdiki durumda birçok sorunu bulunan İstanbul gibi “kirlenmiş, aşırı kalabalıklaşmış ve gitgide soylulaştırılan bir kent”te (Gölönü, 2020: 106) kentsel dönüşümün yaralarına geçici bir çözüm mü sunacağı sorusu yöneltilmektedir. Gölönü söz konusu çalışmasında millet bahçeleri üzerinden soylulaştırmayı destekleyen ve yapı sektörüne yeni kâr olanakları yaratan resmi söylemi karşısına almaktadır. Güncel gazete haberlerine göz atınca, araştırmacıların millet bahçeleri aracılığıyla daha çok kentsel rant elde edilmesine yönelik haklı uyarısı önem kazanmaktadır. Örneğin, bir haberde Sivas, Kütahya ve Bingöl kent belediyelerinin millet kıraathaneleri için milyonlarca liralık ihaleler yaptıkları belirtilmektedir (Bildircin, 2020). Başka bir haberdeyse, millet bahçeleri için Çevre ve Şehircilik Bakanı'nın 202I bütçesine yönelik açıklamalarında dile getirdiği 16 milyar liralık toplam giderin yedi bakanlığın ayrı ayrı bütçesini geçtiği ortaya koyulmaktadır (Millet bahçelerinin maliyeti, 2020).

Millet bahçeleri projesi toplumsal ve kültürel açıdan da değerlendirilebilir. Toplumsal ve kültürel boyut elbette, siyasal ve simgesel-ideolojik boyutlardan bağımsız değildir. Eğer millet bahçeleri ilgili yazında (Birol ve Aydın, 2019) aktarıldığı gibi halka yeşil alan sunmanın yanında, insanların boş zaman kullanımını da ilgilendiriyorsa, "biyopolitika" başlığı altında da tartışmaya açılabilir. Kültürel anlamda, millet bahçeleri bir kent planlaması ürünü olarak, insanların kentte bedenlerini nasıl kullanması beklendiğiyle ilişkilidir ve bu kişisel kentsel hareketliliği yönlendirmeyi amaçlar. Kentlerin, kent parklarının nasıl planlandığı buraları kullanacak insan topluluklarının bu mekânlarda nasıl davranması gerektiğiyle ilgili öngörüleri büyük ölçüde yansıtır ve biçimlendirir. Millet bahçesi projesinde mekânı ve mekânın olanaklarını kararlaştırıp, üreten erkin toplum ülküsü ve kültür tasarımı seçimleri en başta belirleyicidir, çünkü millet bahçeleri diğer birçok kentsel yenileme projesi gibi katılımcı bir anlayışla üretilmemiştir.

Gölönü'nün (2020) dikkat çektiği gibi, adında kamu sözü geçen parkların (public garden) 'kamusal' niteliği çoğu kez tartışmalıdır ve özel sektörün olmayan anlamında kamusal olmaları 
gerçekten halkın oldukları anlamına her zaman gelmeyebilmektedir. Aynı şey, kamusal alanlardaki yayalaştırma projeleri için de söylenebilir. TMMOB Şehir Plancıları Odası'ndan (ŞPO) yetkili bir görüşmecinin Taksim Cumhuriyet Meydanı'nın yayalaştırılmasının meydanın tam olarak halkın kullanımına açılması anlamına gelmeyebileceğiyle ilgili Jacobsvari uyarısı bunun bir örneğidir (Kırmızı, 20I I: I55). Ekinci ve Sağlam (2016) kendi çalışmalarında parkların toplumsal rollerine, anlamlarına ve bunlardaki tarihsel değişime değinmektedirler. Bu yazarlara göre, günümüzde kent parklarının politik ve ekonomik yönleri toplumsal rol ve anlamlarına ağır basarken, yeni parkların yarattıkları kentsel doku eski parklardaki gibi farklı insanları buluşturup, bir araya getirmektense, toplumu ayrıştırıp, kentteki etkileşimleri azaltacak yönde işlemektedir. Yıldırım ve Gül'ün (2020) Samsun Millet Bahçesi örneği çalışmasında parkın doğu ve batı kesimlerinden gelecek farklı kullanıcı topluluklarının parkta bir araya gelmeleriyle oluşabilecek bir tür "uygarlıklar çatışması”na karşı yöneticileri uyarıp, güvenlik önlemleri önermeye gerek duymuş olmaları da günümüz parklarının yarattığı “kentsel doku” (Ekinci ve Sağlam, 2016) bağlamında değerlendirilebilir.

Yazının bundan sonraki bölümünde kent yazınının kült eserlerinden biri olan Büyük Amerikan Kentlerinin Ölümü ve Yaşamı kitabının yazarı olan Amerikalı-Kanadalı yazar ve eylemci Jane Jacobs bugün yaşasaydı, millet bahçesi projesi için ne derdi sorusuna yanıt aranmaktadır. Bunun için, millet bahçeleri konusu Jacobs'un planlama anlayışı ve kent parklarına ilişkin belli başlı düşünceleri ışığında tartışılacaktır. Böylelikle konuyla ilgili yapılmış diğer çalışmalarda eksik olduğu düşünülen planlama boyutunun millet bahçeleriyle ilgili tartışmaya eklenmesi amaçlanmaktadır.

\section{Jane Jacobs'un Mahalle Parklarının Kullanımına ilişkin Genel Düşünceleri}

Jacobs'un millet bahçelerinin yapımına ne diyeceği konusu üzerine düşünmeden önce, Büyük Amerikan Kentlerinin Ölümü ve Yaşamı eserinin ana düşüncesine ve başlıca varsayımlarına ilişkin birkaç noktaya değinmekte yarar var. Jacobs (196I/20I7) bu kitabında kentin sorunlarının çözümünü kentin konut yoğunluğunu, kullanım karmaşasını ve trafiğini azaltıp, seyrekleştirmekte, yani kente karşı (anti-kent) bir çizgide arayan klasik ya da geleneksel planlama anlayışını karşısına almaktadır. Ünlü kent tarihçisi Mumford bile Jacobs'un eleştirilerinden payına düşeni almaktadır. Jacobs bütün kitabı boyunca kent, çevre (muhit), semt, sokak, vb. farklı alan ölçeklerinde canlılık, karmaşık bir düzen, çapraz kullanımlar, yoğunluk ve çeşitlilik vurgusu yapmaktadır. Marks'ın Hegel'in idealizmini ayakları üstüne dikmesi gibi klasik kent planlamasını ayakları üzerine dikmektedir. İnternetteki biyografilerinde Jacobs'un 'alaylı' olduğu için kent uzmanlarınca ciddiye alınmadığından söz edilmektedir. Oysaki tam tersine, bu kitabının genel dü- şünsel tutarlılığı ve her bir bölümündeki ince detayları müthiş bir çözümleyici (analitik) zekâ ürünüdür. Eserin gelecekte daha özenli çevirilerle yeni baskılarının yapılması gerekmektedir, çünkü örneğin, gecekondusuzlaştırma (unslumming) gibi kavramların kent yazınında çok farklı, hatta Jacobs'un önerdiklerinin tam karşıtı anlamlara gelen "mutenalaşma” gibi yanlış çevirileri kent öğrencileri için kafa karıştırıcı olabilmektedir.

Jacobs (196I/2017) kitabının "Mahalle Parkının Kullanımları" başııklı beşinci bölümde bu yazının ele aldığı millet bahçeleri konusuyla ilişkili olan kent parkları sorununu ele almaktadır. Ortodoks kent plancılarının savunduğu "mahallelerde açık alan iyidir" anlayışını "kim ve ne için iyi”" sorularıyla sorgulayarak işe başlamaktadır. Ona göre, başarılı parklar çeşitli toplumsal kesimlerce gün boyu kullanılan ve içerdikleri farklı öğelerin iç içe geçmiş (girift) tasarımları sayesinde kullanıcıların yeniden gitmek isteyecekleri parklardır. Bu anlamda, başarılı parklar Jacobs'un kitabında yeterince kullanılmayan kentsel boşlukları anlatmak için kullandığı "kent vakumları"ndan ya da bu türden kentsel alanları incelediği on dördüncü bölümde nitelediği biçimiyle "kullanım vakumları"ndan (Jacobs, 196I/2017: 278) ayrılmaktadır. Jacobs birer zorunlu kamusal alan olarak değerlendirdiği genel parklara karşılık, çeşitli spor, kültür, eğlence etkinliklerine yönelik kullanımları destekleyen özel amaçlı parklar sınıflandırması üzerinden parkların gerçek ve efsanevi kullanımlarını birbirinden ayırmaktadır. Daha başarısız bulduğu genel parkların kullanılabilirliklerinin artırılması için, tasarımlarında giriftlik, merkezilik, güneş ve kapalıık öğelerinin gerekliliğini vurgulamaktadır.

Jacobs ekolojik anlamda parkların temiz hava sağlaması ve çevresine değer katması savlarına karşı savlar sunmaktadır. Kullanım açısından, parkların birçoğunun kullanımının düşük sayıda kullanıcının günün belirli saatlerindeki kullanımıyla sınırIı kaldığını Philadelphia'daki çeşitli örnekler üzerinden belirtmektedir. San Francisco örneğini vererek, parka bir seçenek olarak "yoğun bir şekilde yeşillendirilmiş çok sayıdaki küçük alan" (Jacobs, 196I/2017: 127) önerisinde bulunmaktadır. Jacobs'un parkların çevresindeki konutlara değer kazandıracağı düşüncesine ilişkin ek bir değerlendirmesiyse, parkların iyi mahalleler değil, mahallelerin iyi parklar yarattığı biçiminde özetlenebilir. Bu düşüncesine mahallenin gelir düzeyinin parkın kullanımının belirleyicisi olmadığı uyarısını da eklemektedir. Jacobs kitabındaki parklarla ilgili bu bölümü parkların kendi başlarına, içinde yer aldıkları kentsel çevre için bir değer ya da sorun olmadığını, gerçekte, kullanımları dışında yalnızca soyut bir değere karşılık geldiklerini ve kendilerini çevreleyen bölgenin bir turnusol kâğıdı olduklarını söyleyerek bitirmektedir.

Jacobs'un kentlere ve mahalle parklarına ilişkin ana düşüncesi özetle şöyledir:

İşlevsel bakımdan çevresinde herhangi bir tek tiplik bulunan genel kullanıma açık bir mahalle parkı günün 
önemli bir kısmında boşluk olmaya mahkûmdur. (...) Şehirlerde canlılık ve çeşitlilik daha fazla canlılı̆̆ı çeker; cansızlık ve monotonluk da hayatı iter, uzaklaştırır. Bu prensip şehirlerin sadece toplumsal davranışları açısından değil, ekonomik davranışları açısından da hayatidir (Jacobs, 196I/2017: I19).

Jacobs'un Amerikan kentleri bağlamında parklar için ayrılan büyük paralar konusundaki görüşleriyse, şöyledir:

Ama boş alanın kendiliğinden iyi ve niceliğin de nitelikle aynı şey olduğu yanılgısına kapılmış günümüz Amerikan şehirleri paralarını fazla büyük, fazla sık, fazla üstünkörü, fazla kötü yerleşimli, dolayısıyla kullanılamayacak kadar yavan ya da elverişsiz parklara, oyun sahalarına ve toplu konut peyzajına harcamaktadır (Jacobs, 1961/2017: 131).

Jacobs'un bu değerlendirmelerinden yola çıkarak, izleyen bölümde Türkiye'deki millet bahçeleri projesi yazarın kent parklarına ilişkin toplumsal kullanım, fiziksel tasarım, güvenlik, ekonomik değer yaratma ve kamu kaynaklarının doğru kullanımı konularındaki düşünceleri çerçevesinde değerlendirilmektedir.

\section{Değerlendirme: Jane Jacobs Millet Bahçelerine Karşı mı?}

Jacobs (196I/2017) kitabında Los Angeles, Boston, Baltimore, New York gibi Amerikan kentlerinden kullanımlarının düşüklüğü nedeniyle, günün büyük bir bölümünde boş kalan park örnekleri vermektedir. Bu görüşe dayanarak denilebilir ki, millet bahçelerinin kullanımları genel, açık-yeşil alan işleviyle sınırlı kaldığı sürece daha yoğun olarak kullanılacağını varsaymak için geçerli bir neden yoktur. Bir olasılıkla, içlerinde yer alması planlanan spora yönelik etkinlik alanları belirli bir sayıda insanı kendine çekebilir. Ancak Yıldırım ve Gül'ün (2020) Samsun Millet Bahçesi'ndeki çeşitli kullanım öğelerinin düşük kalitesinden, hatta olası tehlikelerinden söz ettiklerini, yürüyüş parkurlarındaki şimdiden gözlemledikleri bozulmaları düşününce, parkların insanların yoğun kullanımını taşıma kapasitesi de baştan sorunludur. Tasarımda ve işçilikte gözlemlenen bu kalitesizlik Jacobs'un (196I/2017) genel amaçlı parklar için önerdiği dört tasarım ölçütünün, yani giriftlik, merkezilik, güneş ve kapalılığın millet bahçelerinde ne ölçüde sağlanabileceği konusunda kuşku uyandırmaktadır.

Jacobs'un (196I/2017) eserinde özellikle büyük parkları güvensiz bulduğu görülmektedir. Bunu kitabında park konusundan önce gelen "Çocukların Asimilasyonu” başlıklı bölümde çocukların kentlerdeki güvenliği konusunu incelerken, özellikle vurgulamaktadır. Söz konusu bölümde çocukların kentte güvenle oynayabilmesi için, geniş ve yetişkin gözetiminden uzak parklardansa, işlek sokakların kaldırımlarını önermektedir. Bu önerisini desteklemek için, mahallenin tanınan dükkân sahipleri gibi kamusal karakterlerinin mahallenin çocuklarına gönüllü bir biçimde göz kulak olacağını belirtmektedir. Geniş ve az kullanılan parklar içinse, Jacobs şu yorumu yapmaktadır: "İzleyen gözlerin olmadığı sokaklarla aynı problemleri yaratır, bu tehlike çevredeki alanlara da yayılır ve böyle parklara bitişik sokaklar da tehlikeli sayıldığından boş kalır. Üstelik az kullanılan parklar ve bu parklardaki donatılar şiddete maruz kalır ki burada kesinlikle aşınmadan bahsetmiyoruz," (Jacobs, 196I/20I7: II5). Millet bahçeleri için, bir yetkilinin, "Ama Millet Bahçeleri için ortalama 70.000-80.000 m²'lik alanlardan bahsedebiliriz," (Birol ve Aydın, 2019: 494) sözü anımsanırsa, millet bahçelerinin gelecekte bir güvenlik sorunu yaratabileceği öngörülebilir.

Jacobs (196I/20I7) parkların içinde bulundukları kentsel bölgeye değer kattıkları görüşüne de katılmaz. Ona göre, "parkların taşınmaz mülklerin istikrarını sağladığı ya da muhit sakinlerini yerlerinde tuttuğu yolundaki yanlış kanıyı çöpe atmak da park davranışını anlamak için zorunludur," (Jacobs, 196I/20 I7: II2). Bu nedenle, millet bahçelerinin yapımında eğer kimi güncel haberlerin altını çizdiği gibi, çevrelerindeki lüks konut girişimlere ek kazanç sağlaması amacı güdülüyorsa (Arı, 2020; Evsen, 2020), Jacobs'a göre bu boşuna bir çabadır. Konuyla ilgili TMMOB Şehir Plancıları Ankara Şubesi şu değerlendirmeyi yapmıştır: "Sonuç olarak önerilen Millet Bahçeleri, daha organize bir rant üretim sürecinin parçası olarak lüks konut projelerine hizmet veren, ek getiri sağlayan ve satış-pazarlama unsuru olarak sunulan hukuksuzluğu tetikleyici projeler halini aldı," (Evsen, 2020).

Jacobs parklar üzerinden böyle bir kentsel getiri hedefinin sonunda başarısızlığa uğrayacağını şu sözlerle dile getirmektedir: "Parklar kendiliğinden hiçbir şey değildir ve bu değişken unsurların kıymetleri ya da muhitlerini ve semtlerini istikrara kavuşturması en olmayacak şeydir," (Jacobs, 196I/2017: II2). Öte yandan, ŞPO'nun millet bahçelerinin komşusu olan lüks konutlardan elde edilecek kazancı pekiştirici birer pazarlık aracı yapılmaları uyarısını Türkiye koşullarında dikkate almak gerekir. Bu durumda, millet bahçelerinin gerçekten, halkın yeşil alan gereksinimiyle ilgili bir proje olup, olmadığı sorusu ortaya çıkmaktadır.

Son olarak, millet bahçeleri için ayrılan parasal kaynak konusuna bakıldığında, millet bahçelerinin yapımına ayrılan toplam bütçenin belli başlı birçok bakanlığın 202I yılı bütçesini aştığı haberi (Millet bahçelerinin maliyeti, 2020) ışığında bu projelerin kentler için yapım gideri daha net olarak anlaşılabilir. Millet bahçeleri için belediyelerden çok büyük bir ekonomik kaynak ayrılmaktadır ve bütçesi yetersiz gelen belediyelerde büyükşehir belediyeleri ya da "ILBANK, TOKI ve EMLAK KONUT" (Birol ve Aydın, 2019: 494) gibi kuruluşlar devreye girmektedir.

Jacobs kamusal kaynakların düşük kullanımlı kent vakumları yaratan, genel amaçlı parklar yerine, yüzme, buz pateni, balık 
tutma, konserler, festivaller, vb. özel amaçlarla kullanılacak parklara harcanmasının daha anlamlı olacağını düşünmektedir. Bu noktada şu sorulabilir: Türkiye millet bahçesi ve kıraathanesine toplam 16 milyar lira ayıracak denli varlıklı mıdır? Bu kaynakla AOÇ, Validebağ, Özgürlük Parkı, vb. ülkenin dört bir yanındaki var olan doğal ya da insan yapımı açı-yeşil alanlar iyileştirilip, korunsa ve geri kalanı da güncel pandemi koşullarında eğitim, sağlık, barınma, çalışma olanakları, vb. başka ivedi toplumsal alanlara ayrılsa, ülke insanı için daha anlamlı olabilir mi?

Bütün bu değerlendirmeler ışığında, Jacobs'un Türkiye kentlerinin gündemindeki millet bahçeleri projesini karşısına alacağını söylemek elbette, bir önyargı ya da abartılı bir anlatım değildir. Bu öngörünün Jacobs'un planlama anlayışı ve kent parklarına ilişkin düşüncelerine dayalı başlıca gerekçeleri, olası kullanım yetersizliği, tasarım öğelerindeki eksiklikler, olası güvenlik sorunları, millet bahçelerinin kente değer katması beklentisinin dayanaksızlığı ve kent kaynaklarının yanlış kullanımıdır.

\section{KAYNAKLAR}

Arı, İ. (2020, 21 Mayı). Millet bahçeleri rant projelerine yeşillik oldu. www. birgun.net

Bildircin, M. M. (2020, 16 Aralık). AKP'li belediyeler kıraathanelere çalıştı. www.birgun.net

Birol, S. Ş. ve Aydın, E. (2019). Açık Alan Rekreasyonunda Kent Merkezlerine Yenilikçi Bir Yaklaşım: Millet Bahçeleri. Uluslararası Sosyal Araştırmalar Dergisi, 12 (66), 489-497. http://dx.doi.org/10.17719/jisr.2019.3600

Ceylan, S. ve Bulut, İ. (2019). Salda Gölü özel çevre koruma bölgesinde turizm baskısı, koruma ve sürdürülebilirlik. Türk Coğrafya Dergisi, 73, 79-89.

Çolak, Y. (2020, 22 Aralık). Salda'ya yerleștirilen ahşap üniteler tepkiye neden oldu: Millet bahçesinin ilk adımı. www.birgun.net

Ecevit, B. (2020, 23 Aralık). Salda Gölü çevresinde Millet Bahçesi çalışmasında sona gelindi. www.cumhuriyet.com.tr

Ekinci, Z. ve Sağlam, H. (2016). Meanings and social roles of the republic period urban parks in Ankara. Procedia - Social and Behavioral Sciences, 216, 610-621. https://doi.org/10.1016/j.sbspro.2015.12.038

Evsen, O. (2020, 26 Nisan). Millet bahçeleri değil rant bahçeleri. www.birgun. net

Gökdemir, E. (2019, 6 Eylül). Bomonti Bira Fabrikası Hafızamızdan Silinmeyecek. m.bianet.org/biamag

Gölönü, B. (2020). From graveyards to the "people's gardens": The making of public leisure space in Istanbul. D. Özkan ve G. Baykal Büyüksaraç (Ed.), Commoning the City: Empirical Perspectives on Urban Ecology, Economics and Ethics içinde (s. 104-122). Oxon, OX ve New York, NY: Routledge.

Jacobs, J. (2017). Büyük Amerikan Şehirlerinin Ölümü ve Yaşamı [The Death and Life of Great American Cities] (3. Baskı). Bülent Doğan (Çev.). İstanbul: Metis. (İlk baskı 1961).

Kaştaş Uzun, İ. ve Şenol, F. (2020). Türkiyédeki Kamusal Yeşil Alanların Tarihsel Gelişimi ve Yeni "Millet Bahçeleri". Art-Sanat, 14, 211-240. https://doi.org/10.26650/artsanat.2020.14.0009

Kepenek, Y. (2020, 6 Aralık). Findıklı kanttları. www.birgun.net

Kırmız1, M. (2011). Taksim Republican Square: a field study on socio-economic, form, use and meaning dimensions. (Yayımlanmamış yüksek lisans tezi). Orta Doğu Teknik Üniversitesi/Sosyal Bilimler Enstitüsü, Ankara.

Millet bahçelerinin maliyeti 7 bakanlığın bütçesini solladı. (2020, 14 Aralık). www.cumhuriyet.com.tr

Yıldırım, M. ve Gül. F. (2020). Kentsel Ortak Kullanım Alanlarına Bir Örnek: Samsun Millet Bahçesi. 19 Mayıs Sosyal Bilimler Dergisi, 1 (2), $125-141$. 